\title{
The ATP-binding cassette transporters ABCB1 and $A B C C 1$ are not regulated by hypoxia in immortalised human brain microvascular endothelial cells
}

\author{
Pauline Patak ${ }^{1,2}$, Fengyan Jin ${ }^{1,2}$, Simon T Schäfer ${ }^{3}$, Eric Metzen ${ }^{2}$ and Dirk M Hermann ${ }^{1 *}$
}

\begin{abstract}
Background: ATP-binding cassette transporters at the blood-brain barrier are actively regulated upon ischemic stroke in a way that impedes the access of pharmacological compounds to the brain tissue. The luminal endothelial transporter $A B C B 1$ was recently shown to be increased, whereas the abluminal transporter ABCC1 was decreased on ischemic brain capillaries. In vitro studies using epithelial cells suggested that ABCB1 is regulated during hypoxia in a hypoxia-inducible factor (HIF)-1 $\alpha$-dependent way.

Methods: In order to investigate whether hypoxia might be responsible for the expression changes of $A B C B 1$ and ABCC1 in the ischemic brain, the immortalised human brain microvascular endothelial cell line hCMEC/D3 was exposed to hypoxia (1\%) or anoxia (0\%). Cell lysates were analysed by Western blot to detect the protein expression of ABCB1, ABCC1, HIF-1 $\alpha$ and HIF-2 $\alpha$.

Results: During hypoxia, an accumulation of HIF-1 $\alpha$ and HIF-2 $\alpha$ was noticed in hCMEC/D3 cells that followed different time kinetics. Both HIF-1 $\alpha$ and HIF-2 $\alpha$ abundance increased within $4 \mathrm{~h}$ of hypoxia. HIF-1 $\alpha$ levels decreased to below detection levels within $16 \mathrm{~h}$ of hypoxia, whereas HIF-2 $\alpha$ remained elevated even after $48 \mathrm{~h}$. No changes of $A B C B 1$ and $A B C C 1$ expression were detected, neither on the mRNA nor protein level.

Conclusion: Our data suggests that other factors than hypoxia may be responsible for the expression changes of ATP-binding cassette transporters in the ischemic brain.
\end{abstract}

Keywords: Blood-brain barrier, hypoxia-inducible factor, multidrug resistance, stroke

\section{Background}

ATP-binding cassette (ABC) transporters are efflux proteins that are abundantly expressed at the blood-brain barrier $[1,2]$. ABC transporters protect the brain from toxic compounds, but at the same time they prevent the access of drugs into the brain $[1,2]$. In brain disease, changes of $\mathrm{ABC}$ transporter expression and hence function have been demonstrated to modulate barrier properties [2]. Upon ischemia, $A B C$ transporters are regulated on brain capillary endothelial cells in a coordinated way that impedes the delivery of drugs into the brain. As such, the luminal transporter $\mathrm{ABCB} 1$, which transfers its

\footnotetext{
* Correspondence: dirk.hermann@uk-ussen.de

1 Department of Neurology, University Hospital Essen, Germany

Full list of author information is available at the end of the article
}

substrates from the brain into the blood, was increased [3], whereas the abluminal transporter $\mathrm{ABCC} 1$, which carries its substrates in the opposite direction, i.e. from blood to brain was decreased [4] following middle cerebral artery occlusion (MCAO) in mice. The altered abundance had a major impact on the biodistribution of drugs in the brain and resulted in a poorer delivery of neuroprotective drugs to the post-ischaemic brain, despite a stroke-related impairment of blood-brain barrier integrity $[3,4]$.

Understanding the regulatory mechanisms of the luminal to abluminal $A B C$ transporter balance is an important challenge for brain pharmacology, as it may identify strategies that improve the access of drugs to the brain. Interestingly, the expression of $\mathrm{ABCB} 1$ has previously

\section{C) Biomed Central}


been shown to be regulated in hypoxic epithelial cells in a hypoxia-inducible factor (HIF)- $1 \alpha$-dependent way [5]. Since hypoxia is a major factor contributing to ischemic injury, we were intrigued by the question whether HIF$1 \alpha$-dependent signaling is also responsible for the ischemia-induced expression changes of $A B C$ transporters in endothelial cells. To elucidate this issue, we exposed the cells of the immortalised human brain microvascular endothelial cell line hCMEC/D3 to conditions of ambient hypoxia.

\section{Methods \\ Cell culture}

hCMEC/D3 cells were propagated in Microvascular Endothelial Cell Medium-2 (EGM-2MV; obtained from Lonza, Allendale, NJ, U.S.A.) [6]. Cells from passage 25 to 35 were grown on surfaces coated with $100 \mu \mathrm{g} / \mathrm{ml}$ rat tail collagen type-I (BD Biosciences, Heidelberg, Germany). Cells were plated on collagen-coated $60 \mathrm{~mm}$ dishes and placed in a hypoxia chamber (oxygen concentration: 1\%). In additional studies, HIF- $1 \alpha$ was chemically induced by supplementing the cells with the iron chelator deferoxamine mesylate (DFO) (0.1 mM; Sigma-Aldrich, Deisenhofen, Germany) or the prolyl-4 hydroxylase inhibitor dimethyloxaloyl glycine (DMOG) $(1 \mathrm{mM}$; Alexis Biochemicals, Lörrach, Germany). To generate oxygen concentrations close to anoxia, cells were furthermore incubated in GasPak (BBL) anoxic jars using BD GasPak EZ anoxic container systems (BD Diagnostic Systems, Heidelberg, Germany). The duration of hypoxia or anoxia exposure is specified below. All experiments were performed at least three times.

\section{Antibodies}

The monoclonal antibody against human HIF-1 $\alpha$ (610959) was purchased from BD Biosciences (Heidelberg, Germany). The polyclonal antibody against HIF-2 $\alpha$ (AF 2886) was from R\&D Systems (Wiesbaden-Nordenstadt, Germany). The polyclonal antibody against $\mathrm{ABCB} 1$ (sc-8313) was from Santa Cruz Biotechnology (Santa Cruz, CA, U.S. A.) and the monoclonal antibody against $\mathrm{ABCC} 1$ was purchased from Alexis Biochemicals (Lörrach, Germany). The polyclonal antibody against actin (A2103) was from Sigma-Aldrich. The goat polyclonal, horse radish peroxidase (HRP)-conjugated antibodies raised against rabbit (PO448) and mouse (PO447) IgG were purchased from DAKO (Hamburg, Germany).

\section{Western blots}

Western blotting for $\mathrm{ABCB} 1$ and $\mathrm{ABCC} 1$ was performed as described previously [7]. Briefly, cell lysates were prepared using RIPA lysis buffer (50 mM Tris pH 7.5, 0.1\% SDS, $1 \%$ Nonidet P40, $0.5 \%$ sodium deoxycholate, $2 \mathrm{mM}$
EDTA, $150 \mathrm{mM} \mathrm{NaCl}$ ) containing protease inhibitor cocktail (Roche, Mannheim, Germany). Protein samples were separated on $7.5 \%$ reducing SDS gels and blotted onto PVDF membranes. After the transfer, blocking of unspecific binding sites was achieved by incubation in Tris-buffered saline $(50 \mathrm{mM}$ Tris/ $\mathrm{HCl}, 150 \mathrm{mM} \mathrm{NaCl})$ containing $0.5 \%$ Tween 20 (TBST, pH 7.2) and 5\% skimmed milk. Washed membranes were incubated overnight at $4{ }^{\circ} \mathrm{C}$ with antibody against $\mathrm{ABCB} 1$ (1:1000 in TBST) or ABCC1 (1:200 in TBST) and for $2 \mathrm{~h}$ at $20^{\circ} \mathrm{C}$ with antibody against HIF- $1 \alpha$ (1:1000 in TBST) and HIF$2 \alpha(1: 1000$ in TBST). Following incubation with HRPconjugated secondary antibodies, the target proteins were detected with the enhanced chemoluminescence (ECL) kit (GE Healthcare, Munich, Germany) using an FX7 chemoluminescence documentation system (Peqlab, Erlangen, Germany).

\section{Real time quantitative PCR (rt-PCR)}

Total RNA was extracted from hCMEC/D3 cells with RNeasy Midi Kit (Qiagen, Hilden, Germany) according to manufacturer's protocol. $1 \mu \mathrm{g}$ RNA was reverse-transcribed to cDNA. The following $a b c b 1$ and $a b c c 1$ primers were used: $a b c b 1$ (84 bp): 5', AAA TTG GCT TGA CAA GTT GTA TAT GG; 3', CAC CAG CAT CAT GAG AGG AAG TC; $a b c c 1$ (139 bp): 5', TCT ACC TCC TGT GGC TGA ATC TG; 3', CCG ATT GTC TTT GCT CTT CAT G. In our studies, succinate dehydrogenase (sdha) was analysed as housekeeping gene using primers provided by Qiagen (cat.-no.: QT00059486). Abcb1, abcc1 and sdha mRNA expression was analysed using $\mathrm{SYBR}^{\mathbb{B}}$ green as fluorescent dye (Eurogentec, Verviers, Belgium) on the Step One Plus Real Time PCR Detection System (Applied Biosystems, Darmstadt, Germany) in a two-step rt-PCR. The denaturation steps were performed at $95^{\circ} \mathrm{C}$ for 10 min followed by 40 cycles at $95^{\circ} \mathrm{C}$ for $15 \mathrm{~s}$, and at $60^{\circ} \mathrm{C}$ for $1 \mathrm{~min}$. Rt-PCR was always performed in duplicates, for which mean values were determined. Amounts of cDNA were normalized to $s d h a$ using the $\Delta c t$ method, as previously described [7].

\section{Results}

\section{HIF- $1 \alpha$ and HIF- $2 \alpha$ expression in hCMEC/D3 cell line} during normoxia and hypoxia

To eludicate the impact of cell confluency on hypoxiainducible expression of HIF- $1 \alpha$ and HIF- $2 \alpha$, cells seeded at different densities were exposed to $1 \%$ oxygen for 6 hours and compared with control cells that were simultaneously kept under normoxia with or without the addition of $0.1 \mathrm{mM}$ DFO. Western blot analysis revealed that whereas no HIF- $1 \alpha$ and HIF- $2 \alpha$ protein was detectable in control cells under normoxia, both hypoxia and DFO induced HIF- $1 \alpha$ and HIF- $2 \alpha$ accumulation in hCMEC/D3 


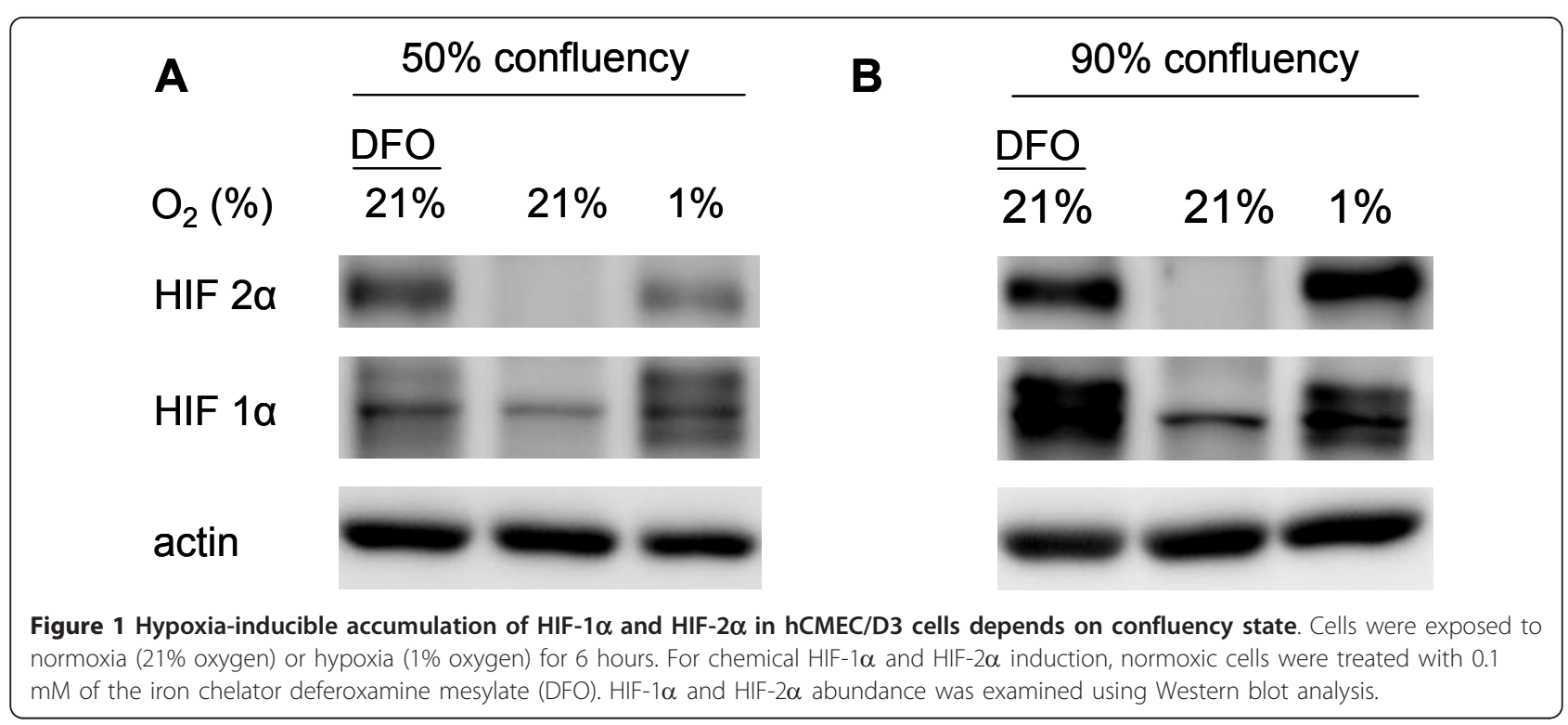

cells (Figure 1A, B). Interestingly, HIF-1 $\alpha$ and HIF-2 $\alpha$ abundance changed with confluency state. As such, both the basal and hypoxic expression of both proteins significantly increased with increasing cell density (Figure 1A, B).

\section{Kinetics of HIF- $1 \alpha$ and HIF- $2 \alpha$ expression in hCMEC/D3 during hypoxia}

To evaluate the kinetics of hypoxic induction of HIF-1 $\alpha$ and HIF-2 $\alpha$, hCMEC/D3 cells were exposed to different durations of hypoxia. Western blot analysis revealed that both proteins were increased when cells were exposed to $1 \%$ oxygen for $4 \mathrm{~h}$ (Figure $2 \mathrm{~A}, \mathrm{~B}$ ). Interestingly, HIF$2 \alpha$ levels continuously remained elevated after 24 and $48 \mathrm{~h}$ hypoxia (Figure 2B). In contrast, HIF-1 $\alpha$ had declined again after $24 \mathrm{~h}$ of oxygen deprivation (Figure 2A). Cells exposed to $1 \mathrm{mM}$ DMOG or $0.1 \mathrm{mM}$ DFO for $4 \mathrm{~h}$ served as positive controls.
$A B C B 1$ and $A B C C 1$ expression remains unchanged in hCMEC/D3 cells during hypoxia and anoxia

Cells exposed to 4 to $48 \mathrm{~h}$ hypoxia or $4 \mathrm{~h}$ anoxia were evaluated by Western blot analysis [7] for changes in the abundance of the $A B C B 1$ and $A B C C 1$ protein. In addition, cells exposed to $4 \mathrm{~h}$ hypoxia were assessed by rt-PCR for changes in $a b c b 1$ and $a b c c 1$ mRNA expression. In none of the experimental conditions examined, changes in $\mathrm{ABCB} 1$ or $\mathrm{ABCC} 1$ protein or $a b c b 1$ and $a b c c 1$ mRNA levels were found (Figures 3 and 4).

\section{Discussion}

We report that $A B C$ transporters are not regulated by hypoxia in the immortalised human brain microvascular endothelial cell line hCMEC/D3, which provides a unique and accessible in vitro system to study protein responses during sustained oxygen deprivation [6]. Our interest was

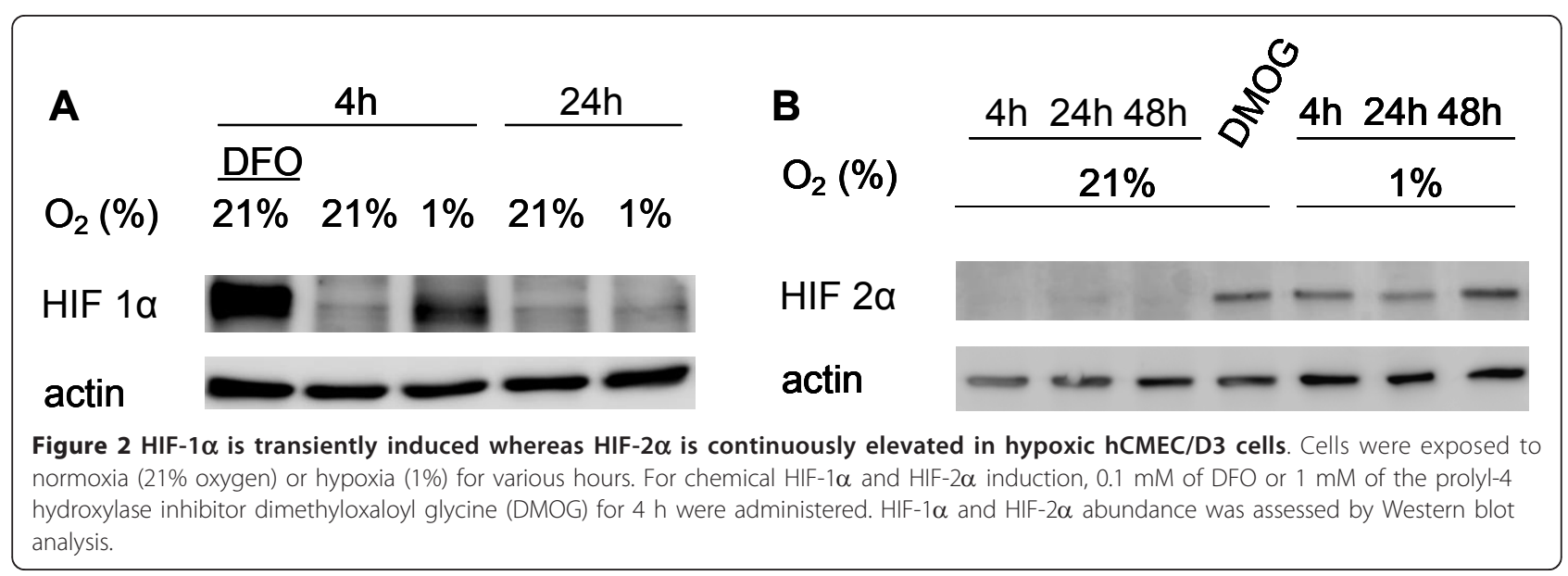




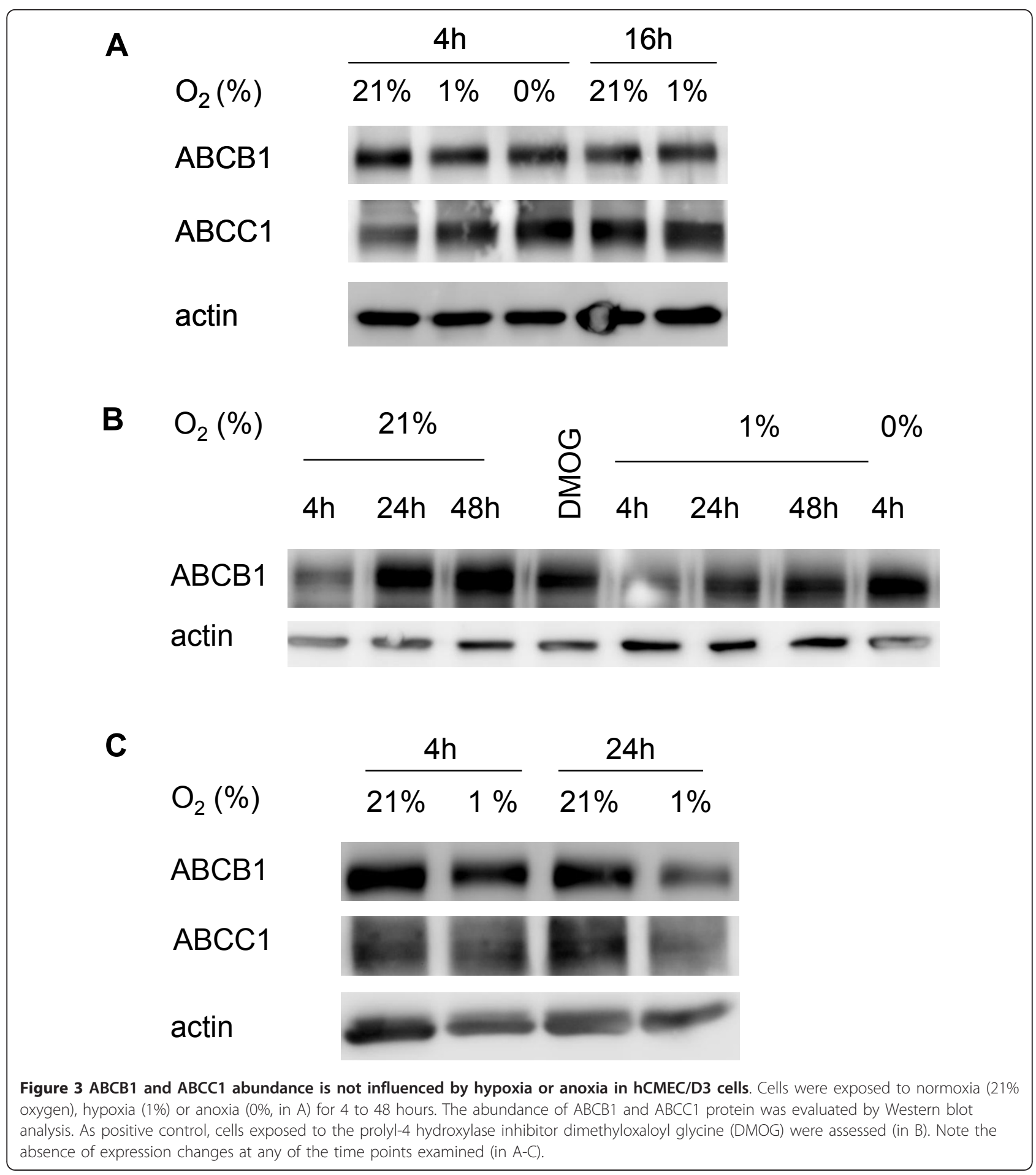

sparked by in vivo studies in a model of MCAO that demonstrated an increase of $\mathrm{ABCB} 1$ [3] and a decrease of $A B C C 1$ [4] protein levels on the surface of ischemic cerebral microvessels. Studies in the epithelial cell lines OKF6, T84 and Caco-2 had shown that the ABCB1 transporter was regulated in a HIF-1 $\alpha$-dependent way upon hypoxia [5]. Thus, we hypothesized that ABCB1 expression in human brain microvascular endothelial cells may also be enhanced as a consequence of HIF activation.

In our study, both HIF-1 $\alpha$ and HIF- $2 \alpha$ were found to be induced upon hypoxia. While HIF- $2 \alpha$ exhibited a 


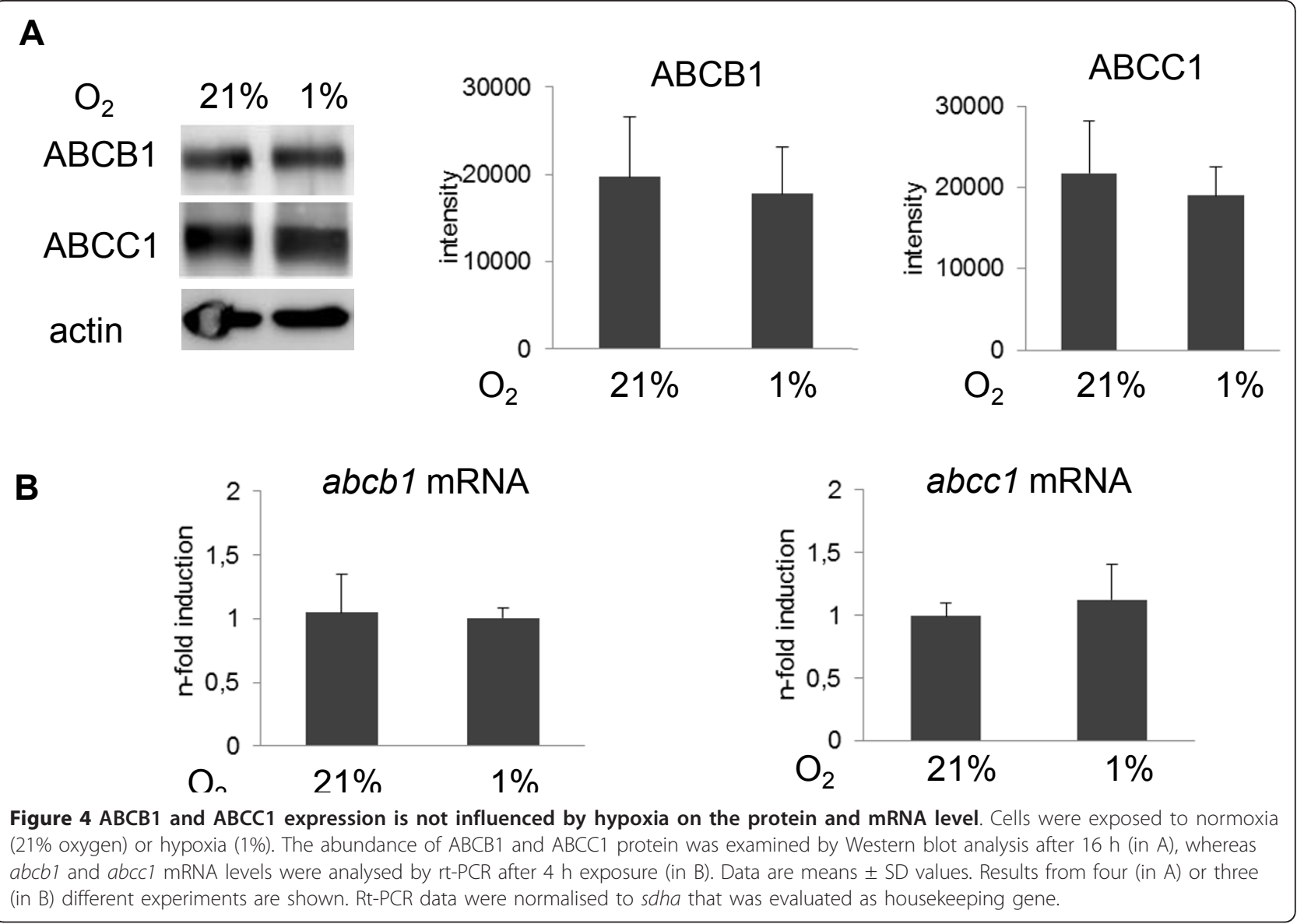

long-lasting accumulation in the brain endothelial cell line, HIF-1 $\alpha$ levels were only transiently increased. While HIF- $1 \alpha$ is known to be expressed in virtually all tissues, HIF- $2 \alpha$ has been shown to be restricted to certain cell types including endothelial cells, cells of the kidney, liver, lungs and pancreas [8]. However, no changes in $\mathrm{ABCB} 1$ or $\mathrm{ABCC} 1$ protein levels were detected in our present study, despite a strong induction of HIF- $1 \alpha$ and HIF- $2 \alpha$ in the hCMEC/D3 cells, suggesting that HIF might not be essential for $\mathrm{ABC}$ transporter regulation in cerebral microvessels. The regulation of both transporters seen in cerebral ischaemia could depend on other factors than hypoxia alone that go hand in hand with ischaemia and have been described to induce $\mathrm{ABCB} 1$ expression, such as glucose depletion [9] or reactive oxygen species that are generated by reoxygenation as shown in rat brain endothelial cells $[10,11]$.

To our knowledge only three other studies have so far examined the effect of hypoxia on $\mathrm{ABC}$ transporters in brain endothelial cells. In a primary rat brain endothelial cell model of hypoxia/reoxygenation, either induced by hydrogen peroxide administration or by reoxygenation following 6 hours of sustained hypoxia, Felix and Barrand
[10] showed increased levels of ABCB1 6 hours following hypoxia and then again 24 hours following reoxygenation. Robertson et al. [11] studied the expression of $\mathrm{ABCB} 1$ in primary and immortalised rat brain endothelial cells that underwent hypoxia/reoxygenation. Exposure of primary rat brain endothelial cells to 6 hours of hypoxia alone revealed no changes in ABCB1 protein levels compared to normoxic controls. Significant increases in ABCB1 levels were only observed $24 \mathrm{~h}$ after $6 \mathrm{~h}$ hypoxia with reoxygenation. Xiao-Dong et al. [12] observed that repetitive hypoxia/reoxygenation may induce an up-regulation of $A B C B 1$ in cultured rat brain microvascular endothelial cells. In that study, cells underwent hypoxia by covering the cells with paraffin oil once daily for 15 min over a time period of 8 days. None of the authors so far investigated the effect of over-night exposure to hypoxia on $\mathrm{ABCB} 1$ levels.

We did not investigate reoxygenation conditions in the present study, since we were interested in the role of HIF- $1 \alpha$ and HIF- $2 \alpha$ in the regulation of ABC transporters. Neither did we investigate $A B C$ transporter expression in co-culture with human astrocytes that are known to have a regulatory function at the blood-brain barrier [13]. Based on the data presented here, it seems that the 
responses of $\mathrm{ABC}$ transporters to hypoxia are less distinct than previously presumed. This is underlined by recent observations in prostate carcinoma cells, showing that the protein expression of $\mathrm{ABCB} 1$ and $\mathrm{ABCC} 1$ were independent of tissue oxygen levels [14]. Our results support the idea that the mechanisms controlling the expression of $\mathrm{ABCB} 1$ and $\mathrm{ABCC} 1$ are cell specific. Thus, hypoxia does not seem to play a major role in the regulation of $\mathrm{ABC}$ transporters in cerebral microvessels.

\section{Conclusion}

This is the first study examining the expression of HIF and $A B C$ transporters under sustained hypoxia in a human cell model of the blood-brain barrier. Despite a strong induction of HIF- $1 \alpha$ and HIF- $2 \alpha$, this study did not detect a regulation of the transporters $\mathrm{ABCB} 1$ and $\mathrm{ABCC} 1$, indicating that neurovascular signals other than HIF- $1 \alpha$ and HIF- $2 \alpha$ are responsible for the expression changes of $\mathrm{ABC}$ transporters after MCAO.

\section{Acknowledgements}

We thank Dr. Pierre-Olivier Couraud (Institut Cochin, INSERM, Paris) for providing hCMEC/D3 cells. Supported by the German Research Foundation (HE3173/2-1 and HE3173/3-1, to D.M.H.) and Heinz-Nixdorf Foundation.

\section{Author details}

${ }^{1}$ Department of Neurology, University Hospital Essen, Germany. ${ }^{2}$ Department of Physiology, University of Duisburg-Essen, Germany. ${ }^{3}$ Department of Anaesthesiology and Intensive Care Medicine, University Hospital Essen, Germany.

\section{Authors' contributions}

PP carried out the cull culture experiments and Western blots and drafted the manuscript. FJ assisted with the Western blots and helped to analyse the data. SS performed the rt-PCR experiments. EM and DMH designed the study, evaluated the data and corrected the draft. All authors read and approved the manuscript.

\section{Competing interests}

The authors declare that they have no competing interests.

Received: 16 October 2011 Accepted: 26 October 2011

Published: 26 October 2011

\section{References}

1. Löscher W, Potschka H: Blood-brain barrier active efflux transporters: ATPbinding cassette gene family. NeuroRx 2005, 2:86-98.

2. Hermann DM, Kilic E, Spudich A, Krämer SD, Wunderli-Allenspach $H$, Bassetti CL: Role of drug efflux carriers in the healthy and diseased brain. Ann Neurol 2006, 60:489-498.

3. Spudich A, Kilic E, Xing H, Kilic U, Rentsch KM, Wunderli-Allenspach $\mathrm{H}$, Bassetti CL, Hermann DM: Inhibition of multidrug resistance transporter-1 facilitates neuroprotective therapies after focal cerebral ischaemia. Nat Neurosci 2006, 9:487-8.

4. Kilic E, Spudich A, Kilic U, Rentsch KM, Vig R, Matter CM, WunderliAllenspach H, Fritschy JM, Bassetti CL, Hermann DM: ABCC1: a gateway for pharmacological compounds to the ischaemic brain. Brain 2008, 131:2679-89.

5. Comerford KM, Wallace TJ, Karhausen J, Louis NA, Montalto MC, Colgan SP: Hypoxia-inducible factor-1-dependent regulation of the multidrug resistance (MDR1) gene. Cancer Res 2002, 62:3387-94.

6. Weksler BB, Subileau EA, Perrière N, Charneau P, Holloway K, Leveque M, Tricoire-Leignel H, Nicotra A, Bourdoulous S, Turowski P, Male DK, Roux F, Greenwood J, Romero IA, Couraud PO: Blood-brain barrier-specific properties of a human adult brain endothelial cell line. FASEB J 2005, 19:1872-4.

7. EIAli A, Hermann DM: Apolipoprotein E controls ATP-binding cassette transporters in the ischemic brain. Sci Signal 2010, 3:ra72.

8. Hu CJ, Wang LY, Chodosh LA, Keith B, Simon MC: Differential roles of hypoxia-inducible factor 1-alpha (HIF-1alpha) and HIF-2alpha in hypoxic gene regulation. Mol Cell Biol 2003, 23:9361-74.

9. Ledoux S, Yang R, Friedlander G, Laouari D: Glucose depletion enhances P-glycoprotein expression in hepatoma cells: role of endoplasmic reticulum stress response. Cancer Res 2003, 63:7284-90.

10. Felix RA, Barrand MA: P-glycoprotein expression in rat brain endothelial cells: evidence for regulation by transient oxidative stress. $J$ Neurochem 2002, 80:64-72

11. Robertson SJ, Kania KD, Hladky SB, Barrand MA: P-glycoprotein expression in immortalised rat brain endothelial cells: comparisons following exogenously applied hydrogen peroxide and after hypoxiareoxygenation. J Neurochem 2009, 111:132-41.

12. Xiao-Dong L, Zhi-Hong Y, Hui-Wen Y: Repetitive/temporal hypoxia increased P-glycoprotein expression in cultured rat brain microvascular endothelial cells in vitro. Neurosci Lett 2008, 432:184-7.

13. Abbott NJ, Rönnbäck L, Hansson E: Astrocyte-endothelial interactions at the blood-brain barrier. Nat Rev Neurosci 2006, 7:41-53.

14. Thews O, Gassner B, Kelleher DK, Gekle M: Activity of drug efflux transporters in tumor cells under hypoxic conditions. Adv Exp Med Biol 2008, 614:157-64.

doi:10.1186/2040-7378-3-12

Cite this article as: Patak et al:: The ATP-binding cassette transporters $A B C B 1$ and $A B C C 1$ are not regulated by hypoxia in immortalised human brain microvascular endothelial cells. Experimental \& Translational Stroke Medicine 2011 3:12

\section{Submit your next manuscript to BioMed Central and take full advantage of:}

- Convenient online submission

- Thorough peer review

- No space constraints or color figure charges

- Immediate publication on acceptance

- Inclusion in PubMed, CAS, Scopus and Google Scholar

- Research which is freely available for redistribution 